\title{
Radioisotope study of small joint inflammation in rheumatoid arthritis
}

\section{Radioactive technetium $\left({ }^{99 \mathrm{~m}} \mathrm{Tc}\right)$ uptake in the proximal interphalangeal joints and the effects of oral corticosteroids}

\author{
K. E. COLLINS, ${ }^{1}$ S. DEODHAR, ${ }^{2}$ G. NUKI, ${ }^{3}$ K. WHALEY, 4 \\ W. WATSON BUCHANAN, ${ }^{5}$ AND W. CARSON DICK 6 \\ From the Centre for Rheumatic Diseases, the University Department of Medicine, Royal Infirmary, Glasgow, \\ and the Western Infirmary, Glasgow
}

Radioactive technetium $\left({ }^{99 \mathrm{~m}} \mathrm{Tc}\right)$, introduced into nuclear medicine in 1964 (Harper, Beck, Charleston, and Lathrop, 1964), has been used to visualize many organs (McCready, 1967), including the thyroid gland (Andros, Harper, Lathrop, and McCardle, 1965), the salivary glands (Harden, Hilditch, Kennedy, Mason, Papadopoulos, and Alexander, 1967b), the stomach (Harden, Alexander, and Kennedy, 1967a; Irvine, Stewart, McLoughlin, and Tothill, 1967), the liver (Sorensen and Archambault, 1963), the brain (Davis, Alexander, Witcofski, and Maynard, 1966), the placenta (Larson and Nelp, 1965), and the joints (Weiss, Maxfield, Murison, and Hidalgo, 1966; Alarcón-Segovia, Trujeque, Tovar, and Adame, 1967; Whaley, Pack, Boyle, Dick, Downie, Buchanan, and Gillespie, 1968; McCarty, Polcyn, and Collins, 1970a; McCarty, Polcyn, Collins, and Gottschalk, 1970b). Technetium scintiphotography of finger and wrist joints and knees in rheumatoid arthritis has shown increased uptake in the joints which reflected the degree of inflammatory involvement at the time of study (Weiss and others, 1966; Alarcón-Segovia and others, 1967; McCarty and others, 1970a), and Whaley and others (1968) have described a technique for quantitating the joint scintiphotographs. Scintiphotography of joints has the major disadvantage of requiring doses of the order of over one millicurie of $99 \mathrm{~m} \mathrm{Tc}$ to obtain adequate contrast between inflamed and normal joints (Whaley and others, 1968; McCarty and others, 1970a) and quantitation of the scintiphotographs is tedious and time-consuming. Recently, Dick, Neufeld, Prentice, Woodburn, Whaley, Nuki, and Buchanan (1970) have reported a method of quantitation in the knee joint based upon the uptake of $99 \mathrm{~m}$ Tc by the joint as measured by continuous external directional counting after the intravenous administration of approximately $40 \mu \mathrm{ci}$ of the isotope. This method was shown to be reproducible when repeat measurements were made within $24 \mathrm{hrs}$, to reflect differences between normal and inflamed joints affected by rheumatoid arthritis, and to be capable of reflecting the effects of intra-articular injection of corticosteroids (Dick and others, 1970). In this paper we describe similar studies carried out on the proximal interphalangeal joints.

\section{Material and methods}

\section{SUBJECTS}

28 patients with definite or classical rheumatoid arthritis, as defined by the diagnostic criteria of the American Rheumatism Association (Ropes, Bennett, Cobb, Jacox, and Jessar, 1959) took part in the study. There were 27 females, and one male. The mean age was 56.7 yrs (range 22 to 76 ).

Thirteen healthy volunteers ( 8 females, 5 males) with a mean age $23 \cdot 1$ yrs (range 22 to 35 ) served as controls. All patients and control subjects volunteered to participate in this study with full knowledge of its content.

\section{ISOTOPE STUDIES}

Approximately $200 \mu \mathrm{ci}$ (standardized by count rate) of ${ }_{99 \mathrm{mTc}}$ in $1 \mathrm{ml}$. sterile $\mathrm{NaCl}$ was administered intravenously into a vein in the antecubital fossa of the left arm. Within one minute after the injection the count rate was monitored continuously for $15 \mathrm{~min}$. over the proximal interphalangeal joint of the index finger of the right hand. Peak values were then obtained for the other proximal

\footnotetext{
Fourth year medical student, University of Glasgow.

Registrar in Medicine, Centre for Rheumatic Diseases, and University Department of Medicine, Royal Infirmary, Glasgow C-4.

- CIBA Clinical Research Fellow and Honorary Senior Registrar in Medicine, Centre for Rheumatic Diseases, Glasgow C-4.

MRC Research Fellow and Honorary Registrar in Medicine, Centre for Rheumatic Diseases, Glasgow C-4, and University Department of Medicine and Pathology, Western Infirmary, Glasgow W.1.

- Physician in Charge, Centre for Rheumatic Diseases and Consultant in Medicine, University Department of Medicine, Royal Infirmary, Glasgow C-4.

- Lecturer in Medicine, University Department of Medicine, Royal Infirmary, Glasgow C-4. (Requests for reprints.)

Accepted for publication December 23, 1970.
} 
interphalangeal joints, counting for one minute over each joint. The sequence of counting was consistent, being from the first to fourth proximal interphalangeal joints, the right hand being counted first. In previous feasibility studies, it had been noted that excess $90 \mathrm{mTC}$ counts were occasionally present over the site of the intravenous injection when compared with the identical area on the opposite arm at the conclusion of the study. Because of this, great care was exercised to ensure that the injection was truly intravenous, and verification that the total dose of ${ }^{00 \mathrm{~m} T c}$ had been administered intravenously was carried out by washing the syringe through with intravenous blood and by comparing counts at the injection site with the corresponding site on the right arm at the end of the study. In no instance were excess counts recorded at the site of injection.

During the isotopic studies the patient's hand was positioned on blocks of adjustable height below a lead shield $0.5 \mathrm{~cm}$. thick with an aperture $2 \mathrm{~cm}$. in diameter. The joint to be counted was placed directly below the aperture, the counter resting on the shield which was supported by two lead supports $6 \mathrm{~cm}$. high and $12 \mathrm{~cm}$. apart. The counting equipment consisted of a collimated $1 \times 1.5$ in. thallium-activated sodium iodide crystal connected through an ECKO ratemeter (M5 180) and pulse height analyser (M 5010) to a Kienzle automatic print-out. The initial count rate per $10 \mathrm{sec}$. was $15,000 \pm$ 3 per cent. at 16 in., and the background of the order of
50 to 100 counts $/ 10 \mathrm{sec}$. The results were related to the dose administered, and expressed as a percentare of the administered dose corrected for counting geometry.

Repeat uptakes of $90 \mathrm{mTc}$ in the proximal interphalangeal joints were measured in nine patients at $24 \mathrm{hrs}$ to determine the reproducibility of the measurement.

The effects of oral prednisolone therapy $5 \mathrm{mg}$. twice daily on the proximal interphalangeal joint uptakes of $99 \mathrm{mTc}$ were studied in seven patients. The effects on $99 \mathrm{mTc}$ uptakes were compared with the joint circumference as measured by a plastic spring gauge (Geigy Ltd) described by Boardman and Hart (1967) and with the grip strength as measured by the mean of three readings over a baseline of $30 \mathrm{~mm}$. $\mathbf{H g}$ for each hand. Before each isotope study each joint was assessed by the same observer (K.C.). A history of pain and of stiffness was elicited and graded. Firm pressure was exerted over the joint margin and the response graded. An assessment of the degree of joint warmth and swelling was graded. Grading was on a 0 to 3 basis: $0=$ absent; $1=$ slight; $\mathbf{2}=$ moderate; $\mathbf{3}=$ severe. The maximum score for an individual joint was $1+15$.

\section{Results}

Table I summarizes the results of repeat ${ }^{00 \mathrm{~m} T c}$ uptakes in the eight proximal interphalangeal joints in nine patients at $\mathbf{2 4} \mathrm{hrs}$. In all eight joints the mean

Table I Repeat ${ }^{90 \mathrm{~m}}$ Tc uptakes (per cent. $\times 10^{-2}$ ) in proximal interphalangeal joints in nine patients with

Hand

Right

\begin{tabular}{|c|c|c|c|c|c|}
\hline & & & & & \\
\hline & 1 & 2 & 3 & 4 & Total \\
\hline \multirow[t]{2}{*}{$\begin{array}{l}\text { 99mTc uptakes } \\
\text { (per cent. } \times 10^{-2}\end{array}$} & $8 \cdot 24 \pm 0 \cdot 83$ & $6 \cdot 75 \pm 0 \cdot 70$ & $6.48 \pm 0.82$ & $5 \cdot 87 \pm 0.73$ & $6.85 \pm 0.69$ \\
\hline & $8 \cdot 17 \pm 0 \cdot 83$ & $7.04 \pm 0.66$ & $6 \cdot 30 \pm 0.68$ & $6.02 \pm 0.87$ & $6.89 \pm 0.66$ \\
\hline $\begin{array}{l}\text { Mean } \pm \text { SE mean of } \\
\text { difference }\end{array}$ & $0.05 \pm 0.26$ & $0.28 \pm 0.49$ & $0.23 \pm 0.43$ & $0.17 \pm 0.42$ & $0.12 \pm 0.40$ \\
\hline
\end{tabular}

Table III ${ }^{99 \mathrm{~m}} \mathrm{Tc}$ uptakes (per cent. $\left.\times 10^{-2}\right)$ and joint circumference $(\mathrm{mm}$.$) of proximal interphalangeal joints$

\begin{tabular}{|c|c|c|c|c|c|c|}
\hline \multirow[t]{2}{*}{ Hand } & & \multicolumn{5}{|l|}{ Right } \\
\hline & & 1 & 2 & 3 & 4 & Total \\
\hline \multirow{4}{*}{$\begin{array}{l}\text { 90mTc } \\
\text { uptakes } \\
\left.\text { (per cent. } \times 10^{-3}\right)\end{array}$} & Before & $6 \cdot 23 \pm 0.12$ & $7 \cdot 50 \pm 0.46$ & $6.34 \pm 0.43$ & $4 \cdot 28 \pm 0 \cdot 38$ & $6.09 \pm 0.26$ \\
\hline & After & $3.94 \pm 0.35$ & $5.28 \pm 0.55$ & $4 \cdot 50 \pm 0 \cdot 34$ & $3 \cdot 74 \pm 0.20$ & $4 \cdot 37 \pm 0 \cdot 28$ \\
\hline & $\mathbf{t}$ & $8 \cdot 14$ & $2 \cdot 96$ & $5 \cdot 20$ & $1 \cdot 17$ & $4 \cdot 84$ \\
\hline & $\mathbf{P}$ & $<0.001$ & $<0.05$ & $<0.01$ & - & $<0.01$ \\
\hline \multirow{4}{*}{$\begin{array}{l}\text { Joint } \\
\text { circumference } \\
\text { (mm.) }\end{array}$} & Before & $59 \cdot 86 \pm 1 \cdot 60$ & $62 \cdot 00 \pm 0.62$ & $59 \cdot 57 \pm 1 \cdot 32$ & $49 \cdot 71 \pm 0.68$ & $57 \cdot 51 \pm 0.80$ \\
\hline & After & $59 \cdot 43 \pm 1.56$ & $60 \cdot 14 \pm 0.55$ & $57 \cdot 86 \pm 1 \cdot 14$ & $48.00 \pm 1.02$ & $56.44 \pm 0.88$ \\
\hline & $\mathrm{t}$ & $1 \cdot 44$ & 4.04 & $2 \cdot 83$ & 2.05 & $4 \cdot 34$ \\
\hline & $\mathbf{P}$ & - & $<0.01$ & - & 一 & $<0.01$ \\
\hline
\end{tabular}


of the differences and the standard errors of the differences are acceptably small. The mean difference for eight studies was $\mathbf{0 . 6 6}$ with a standard error of the difference of $0 \cdot 36$.

Table II summarizes the results of the mean and SEM of the ${ }^{90 \mathrm{~m} T c}$ uptakes in the proximal interphalangeal joints of each hand in thirteen nonarthritic healthy controls and in 22 patients with rheumatoid arthritis. The uptake in all the joints was significantly higher $(P<0.001)$ in the rheumatoid patients. No significant difference was noted in any of the mean uptakes in the proximal inter- phalangeal joints in the normal patients. However, in the patients with rheumatoid arthritis, the mean uptakes in the first three right proximal interphalangeal joints were significantly higher than the mean uptake in the fourth right proximal interphalangeal joint $(P<0.025)$, and in the left hand the mean uptake in the fourth left proximal interphalangeal joint was significantly lower $(P<0.05)$ than the mean uptakes in the first three proximal interphalangeal joints.

The effects of prednisolone $10 \mathrm{mg}$./day for one week on the ${ }^{99 \mathrm{~m} T c}$ uptakes and joint circumferences

Table II ${ }^{99} \mathrm{~m} T c$ uptakes (per cent. $\left.\times 10^{-2}\right)$ in proximal interphalangeal joints (Mean $\pm S E$ mean)

\begin{tabular}{|c|c|c|c|c|c|c|c|c|}
\hline \multirow[t]{2}{*}{ Hand } & \multicolumn{4}{|l|}{ Right } & \multicolumn{4}{|l|}{ Left } \\
\hline & 1 & 2 & 3 & 4 & 1 & 2 & 3 & 4 \\
\hline $\begin{array}{c}\text { Clinical group } \\
\text { Normal (13) } \\
\text { Rheumatoid } \\
\text { arthritis (22) }\end{array}$ & $\begin{array}{l}3 \cdot 11 \pm 0 \cdot 29 \\
5 \cdot 79 \pm 0 \cdot 31\end{array}$ & $\begin{array}{l}3.00 \pm 0.25 \\
6.61 \pm 0.44\end{array}$ & $\begin{array}{l}2 \cdot 93 \pm 0 \cdot 25 \\
5 \cdot 82 \pm 0 \cdot 36\end{array}$ & $\begin{array}{l}2 \cdot 60 \pm 0 \cdot 23 \\
4 \cdot 77 \pm 0 \cdot 34\end{array}$ & $\begin{array}{l}3 \cdot 32 \pm 0 \cdot 34 \\
6 \cdot 23 \pm 0 \cdot 40\end{array}$ & $\begin{array}{l}3.07 \pm 0.32 \\
6 \cdot 32 \pm 0.41\end{array}$ & $\begin{array}{l}2.67 \pm 0.21 \\
6.23 \pm 0.35\end{array}$ & $\begin{array}{l}2 \cdot 36 \pm 0 \cdot 26 \\
5 \cdot 24 \pm 0 \cdot 34\end{array}$ \\
\hline$\underset{\mathbf{P}}{\text { Significance } \mathbf{t}}$ & $\begin{array}{l}5.823 \\
<0.001\end{array}$ & $\begin{array}{l}5.999 \\
<0.001\end{array}$ & $\begin{array}{l}5.687 \\
<0.001\end{array}$ & $\begin{array}{l}4.527 \\
<0.001\end{array}$ & $\begin{array}{l}4.849 \\
<0.001\end{array}$ & $\begin{array}{l}5.354 \\
<0.001\end{array}$ & $\begin{array}{l}7.089 \\
<0.001\end{array}$ & $\begin{array}{l}5.739 \\
<0.001\end{array}$ \\
\hline
\end{tabular}

rheumatoid arthritis at 24 hrs (Mean $\pm S E$ mean)

Left

Both

\begin{tabular}{|c|c|c|c|c|c|}
\hline 1 & 2 & 3 & 4 & Total & \\
\hline $6 \cdot 54 \pm 0.64$ & $6 \cdot 51 \pm 0 \cdot 51$ & $6 \cdot 82 \pm 0.64$ & $5 \cdot 63 \pm 0.63$ & $6 \cdot 15 \pm 0 \cdot 54$ & $6 \cdot 23 \pm 0.43$ \\
\hline $6.86 \pm 0.73$ & $7 \cdot 64 \pm 0.79$ & $7 \cdot 26 \pm 1 \cdot 03$ & $7 \cdot 29 \pm 0.82$ & $7 \cdot 26 \pm 0 \cdot 76$ & $6.92 \pm 0.64$ \\
\hline $0 \cdot 36 \pm 0.40$ & $1 \cdot 13 \pm 0 \cdot 44$ & $0.44 \pm 0.62$ & $1 \cdot 66 \pm 0.56$ & $1.09 \pm 0.37$ & $0.66 \pm 0.36$ \\
\hline
\end{tabular}

before and after one week's oral prednisolone therapy (Mean $\pm S E$ mean)

\begin{tabular}{|c|c|c|c|c|c|}
\hline \multicolumn{5}{|l|}{ Left } & \multirow[t]{2}{*}{ Both } \\
\hline 1 & 2 & 3 & 4 & Total & \\
\hline $6.07 \pm 0.31$ & $6 \cdot 17 \pm 0 \cdot 16$ & $6 \cdot 40 \pm 0 \cdot 22$ & $5 \cdot 06 \pm 0 \cdot 32$ & $5 \cdot 89 \pm 0 \cdot 18$ & $5 \cdot 99 \pm 0 \cdot 16$ \\
\hline $4 \cdot 96 \pm 0 \cdot 32$ & $5 \cdot 40 \pm 0 \cdot 36$ & $4 \cdot 58 \pm 0 \cdot 36$ & $3 \cdot 88 \pm 0 \cdot 29$ & $4 \cdot 70 \pm 0 \cdot 25$ & $4 \cdot 53 \pm 0 \cdot 24$ \\
\hline $3 \cdot 15$ & $2 \cdot 07$ & $7 \cdot 11$ & $3 \cdot 26$ & $6 \cdot 59$ & $5 \cdot 93$ \\
\hline$<0.02$ & - & $<0.001$ & $<0.02$ & $<0.001$ & $<0.01$ \\
\hline $59 \cdot 29 \pm 1 \cdot 21$ & $60 \cdot 43 \pm 1 \cdot 43$ & $57 \cdot 14 \pm 1 \cdot 10$ & $50 \cdot 29 \pm 1 \cdot 02$ & $57 \cdot 27 \pm 0 \cdot 90$ & $57 \cdot 43 \pm 0.65$ \\
\hline $58 \cdot 71 \pm 1 \cdot 34$ & $59 \cdot 29 \pm 1 \cdot 67$ & $56 \cdot 29 \pm 1 \cdot 15$ & $49 \cdot 43 \pm 1 \cdot 32$ & $55 \cdot 93 \pm 1 \cdot 13$ & $55.80 \pm 0.99$ \\
\hline $1 \cdot 9$ & $1 \cdot 6$ & $2 \cdot 1$ & $1 \cdot 87$ & $2 \cdot 51$ & $3 \cdot 36$ \\
\hline- & - & - & - & $<0.05$ & $<0.02$ \\
\hline
\end{tabular}


of the proximal interphalangeal joints are summarized in Table III. With the exception of the fourth right and second left proximal interphalangeal joints, the ${ }^{90 \mathrm{~m} T c}$ uptakes were significantly reduced with prednisolone therapy, as tested by Student's $t$ test for paired values. In each proximal interphalangeal joint, the mean of the differences before and after prednisolone therapy exceeds the mean of the differences observed in the reproducibility study, with the exception of the left fourth proximal interphalangeal joint, where the mean of the differences in the prednisolone trial was $1 \cdot 18 \pm$ SEM $0 \cdot 36$, whereas in the reproducibility study it was $1.66 \pm$ SEM 0.56 . This casts doubt on the validity of the significance value for the fourth left proximal interphalangeal joint.

When each joint was considered individually significant reduction in joint circumference was observed in only the second right proximal interphalangeal joint. However, when mean of the four joints in each hand, and the mean of all eight joints were considered the differences were statistically significant (Table III).

The mean and SEM of three readings for grip strength in the right and left hands was 76.29 \pm 10.42 and $88.71 \pm 11.96 \mathrm{~mm}$. $\mathrm{Hg}$ respectively, and after prednisolone therapy the respective values were $94.14 \pm 9.77$ and $107.7 \pm 13.08 \mathrm{~mm}$. Hg. Although increased in both hands, the differences were not statistically significant in either hand as tested by Student's $t$ test for paired values.

There was no significant correlation between any of the clinical features studied, joint circumference or grip strength and ${ }^{99 \mathrm{~m}} \mathrm{Tc}$ uptake in any of the fingers, or individually in the means of these parameters in either hand.

\section{Discussion}

Rheumatoid arthritis is an inflammatory polyarthritis affecting both large and small joints. Radioactive isotopes have mostly been employed to assess inflammation in large joints, McCarty and others $(1970 \mathrm{a}, \mathrm{b})$ have published scintiphotographs of small joints in the hands demonstrating increased localization of radioactive technetium in inflamed tissue. If, as we consider, the major application of radioactive technetium in arthritis is to provide a method of assessment of anti-inflammatory drug effect, then it is clearly essential that it be susceptible of quantitation, that it be reproducible, that clinically acceptable doses of the tracer be used, and that the effect show changes with conventional doses of antiinflammatory compounds.

In the present study we have employed an extremely low tracer dose of radioactive technetium (less than $200 \mu \mathrm{ci}$ ), and have been able to show clear differences in uptakes between normal and inflamed proximal interphalangeal joints, when considered individually or as a mean for each or both hands. In order to obtain adequate definition in technetium scintiphotography, large doses of radioactive technetium of the order of millicuries are necessary (Whaley and others, 1968; McCarty and others, $1970 \mathrm{a}, \mathrm{b})$. This method affords the opportunity of defining localization of radioactive technetium within the joint, but the high doses required severely limit the number of repeat observations possible. Although the advantage of definition within the joint is sacrificed in the present technique, nevertheless the very small doses of the isotope employed allow frequent repeat observations such as are required to follow anti-inflammatory drug effect without exposing either patient or physician to undue radiation hazard.

Repeat observations within $24 \mathrm{hrs}$ were associated with an acceptably high degree of reproducibility. Changes after one week's oral treatment with low dose corticosteroid therapy were clearly demonstrated when the means of the four proximal interphalangeal joints of each hand and the means of all eight proximal interphalangeal joints were considered. That it is probably preferable to consider the mean values for either or both hands rather than for individual joints is suggested by the fact that changes were not demonstrable in two of the joints studied.

Changes were observed in joint circumference before and after corticosteroid therapy. These changes were significant when the means of the values for either hand or for the mean of both hands were considered. In only one individual joint, however, was the change significant. This finding accords with the suggestion that it is preferable to consider the mean values rather than the values of individual joints. Although no significant correlation was found between any of the clinical parameters of inflammation, joint circumference, or grip strength in individual joints, or in mean values for either or both hands and the technetium uptake, there was a relationship $(r=0.69 ; P=0.05)$ between the degree of change in both technetium uptake and joint circumference before and after corticosteroid therapy. McCarty and others (1970a) have shown a high correlation between scintiphotography and clinical assessment. The reason for the discrepancy between their results and ours is not immediately apparent. These workess have also shown that isotope studies may be positive before clinical expression of disease. It is possible that the isotope studies are therefore more sensitive than is clinical assessment.

The difference in grip strength before and after corticosteroid therapy was not statistically significant. In this study, therefore, the changes exerted by corticosteroid therapy were most apparent in the 
isotope studies, and less obvious in either joint circumference and grip strength. It is possible that the technetium count rate provides a more sensitive index of change with anti-inflammatory drug therapy than that afforded by joint circumference or gi ip strength. Further studies on this point are clearly indicated, and are currently in progress.

\section{Summary}

A simple radioisotopic method for the study of inflammation in the proximal interphalangeal joints in patients with rheumatoid arthritis is described.
The tracer dose of radioactive technetium is extremely small, permitting frequent repeat observations. The method is reproducible and shows differences between normal and inflamed joints. Raised uptakes can be reduced by low dose corticosteroid therapy. The method may prove to be a more sensitive means of measurement than joint circumference and grip strength.

The authors wish to acknowledge the financial support of the Arthritis and Rheumatism Council of Great Britain. The isotope equipment was provided by the National Fund for Research intc Crippling Diseases. One of us (G.N.) was a CIBA clinical research fellow.

\section{References}

Alarcón-Segovia, D., Trujeque, M., Tovar, E., and Adame, M. A. (1967) Arthr. and Rheum., 10, 262 (Scintillation scanning of joints with Technetium-99m).

ANDROS, G., HARPER, P. V., LATHROP, K. A., AND MCCARDLE, R. J. (1965) J. clin. Endocr., 25, 1067 (Pertechnetate- ${ }^{99} \mathrm{~m}$ localization in man with applications to thyroid scanning and the study of thyroid physiology).

Boardman, P. L., ANd Hart, F. Dudley (1967) Brit. med. J., 4, 264 (Clinical measurement of the anti-inflammatory effects of salicylates in rheumatoid arthritis).

Davis, C. H., JR., AleXander, E., JR., WitcofSki, R. L., AND MaYnard, C. D. (1966) J. Neurosurg., 24,987 (Brain scanning with ${ }^{99} \mathrm{~m}$ Technetium).

Dick, W. C., Neufeld, R. R., Prentice, A. G., Woodburn, A., Whaley, K., Nuki, G., and Buchanan, W. W. (1970) Ann. rheum. Dis., 29, 135 (Measurement of joint inflammation: a radioisotopic method).

HaRden, R. MCG., AleXANDer, W. D., AND KenNedy, I. (1967 a) Lancet, 1, 1305 (Isotope uptake and scanning

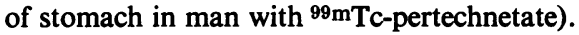

- Hilditch, T. E., Kennedy, I., Mason, D. K., Papadopoulos, S., and Alexander, W. D. (1967b) Clin. Sci., 32, 49 (Uptake and scanning of the salivary glands in man using pertechnetate- $99 \mathrm{mTC}$ ).

Harper, P. V., Beck, R., Charleston, D., and Lathrop, K. A. (1964) Nucleonics, 22, 50 (Optimization of a scanning method using $\mathrm{Tc}^{99} \mathrm{~m}$ ).

IRvine, W. J., STewart, A. G., McLoughlin, G. P., AND Tothill, P. (1967) Lancet, 2, 648 (Appraisal of the application of $99 \mathrm{mTc}$ in the assessment of gastric function).

Larson, S. M., AND NelP, W. B. (1965) Amer.J. Obstet. Gynec., 93, 950 (Visualization of the placenta by radioisotope photoscanning using technetium ${ }^{99 \mathrm{~m}}$-labeled albumin).

McCarty, D. J., Polcyn, R. E., AND Collins, P. A. (1970a) Arthr. and Rheum., 13, 21 (99m technetium scintiphotography in arthritis: II. Its nonspecifity and clinical and roentgenographic correlations in rheumatoid arthritis).

,,,--- AND GotTSCHALK, A. (1970b) Ibid., 13, $11(99 \mathrm{~m}$ technetium scintiphotography in arthritis: I. Technic and interpretation).

MCCREADY, V. R. (1967) Brit. J. Radiol., 40, 401 (Clinical radioisotope scanning).

Ropes, M. W., Bennett, G. A., CobB, S., Jacox, R., AND Jessar, R. A. (1959) Ann. rheum. Dis., 18, 49 (Diagnostic criteria for rheumatoid arthritis; 1958 revision).

Sorensen, L. B., AND ARChambault, M. (1963) J. Lab. clin. Med., 62, 330 (Visualization of the liver by scanning with $\mathrm{Mo}^{99}$ (molybdate) as tracer).

Weiss, T. E., MaXfield, W. S., Murison, P. J., and Hidalgo, J. U. (1966) Sth. med. J., 59, 484 (Scintillation scanning in rheumatoid arthritis).

Vhaley, K., Pack, A. I., Boyle, J. A., Dick, W. C., Downie, W. W., Buchanan, W. W., and Gillespie, F. C. (1968) Clin. Sci., 35, 547 (The articular scan in patients with rheumatoid arthritis: a possible method of quantitating joint inflammation using radio-technetium). 